Torimaru, T., U. Wennström, B. Andersson, C. AlMQVIST and X.-R. WANG (2013): Reduction of pollen contamination in Scots pine seed orchard crop by tent isolation. Scand J For Res 28(8): 715-723.
VIKAS, R. T. (2011): Reproductive biology of Azadirachta indica (Meliaceae), a medicinal tree species from arid zones. Plant Species Biology 26(1): 116-123.

\title{
Morphological characterization and in vitro germination of heat-treated pollen in Eucommia ulmoides
}

\author{
By S. Song ${ }^{1), 2), 3), 5)}$, J. Tian ${ }^{4), 5)}$, Y. Li ${ }^{1), 2), 3), 5)}$, F. Shang ${ }^{1), 2), 3)}$, X. KAnG ${ }^{1), 2), 3)}$ and J. WANG ${ }^{1), 2), 3), *)}$
}

(Received 27th March 2015)

\begin{abstract}
Polyploid breeding has the potential to increase the economic secondary metabolites of Eucommia ulmoides. However, pollination with induced ploidy-mixed pollen has failed to produce polyploids (GAO, 2006). In this investigation, the morphological characterization and in vitro germination of heat-induced ploidy-mixed pollen of $E$. ulmoides were analysed to determine why there is no polyploid production. Heat-treated pollen grains were easily distinguished as large and small according to their length. The large pollen grains were significantly longer than both untreated and heattreated small samples, suggesting that they were probably $2 \mathrm{n}$ pollen. Rather than the three germinal pores in small pollen, the large grains typically had four pores and, in some cases,

1) National Engineering Laboratory for Tree Breeding, Beijing Forestry University, Beijing 100083, People's Republic of China.

$\left.{ }^{2}\right)$ Key Laboratory of Genetics and Breeding in Forest Trees and Ornamental Plants, MOE, Beijing Forestry University, Beijing 100083, People's Republic of China.

$\left.{ }^{3}\right)$ College of Biological Sciences and Technology, Beijing Forestry University, Beijing 100083, People's Republic of China.

$\left.{ }^{4}\right)$ The Academy of Forestry, Beijing Forestry University, Beijing 100083, People's Republic of China.

5) SHAOYU SONG, JU TIAN and YUN Li contributed equally to this work.

*) Address correspondence to: P. O. Box 118, Beijing Forestry University, NO.35, Tsinghua East Rd., Haidian District, Beijing 100083, People's Republic of China. Tel.: +86-10-62338105.

E-Mail: wangjun@bjfu.edu.cn
\end{abstract}

shallow furrows, which might affect their germination. Although the maximal germination rates of the treated small and large pollen were not significantly different, the large pollen germinated tardily during the early stages of incubation. The small pollen maintained its growth during the incubation, but the tube growth of large pollen almost stopped after $24 \mathrm{~h}$ incubation. Both vegetative and generative nuclei in the large pollen moved into tubes later than in small pollen and the frequency of mitosis in generative nuclei of large pollen was low. Therefore, the tardy germination, poor tube growth, and weak activity of both vegetative and generative nuclei probably caused the poor competition of large pollen in certation. Finally, techniques to increase the competition of highploidy pollen and the prospect of $2 \mathrm{n}$ female gamete induction in the polyploid breeding program of E. ulmoides are discussed.

Key Words: Eucommia ulmoides Oliver; heat-treated pollen; polyploid breeding; poor competition; tardy germination

\section{Introduction}

Eucommia ulmoides Oliver $(2 \mathrm{n}=2 \mathrm{x}=34)$, an endangered deciduous tree species distributed in central and eastern China, is an important economic resource for the herbal medicine and the organic chemical industry (YAO et al., 2012). Some phytochemicals of $E$. ulmoides leaves have been demonstrated to exhibit a wide range of biological activities, such as antioxidant activity, 
glycation inhibitory activity and anti-obesity activity (DAI et al., 2013). In addition, E. ulmoides is one of the best-known trans-polyisoprene rubber producers, contributing to the raw materials used in golf balls, dental supplies and submarine cables, rather than the synthetic rubber derived from fossil fuels (NAKAZAWA et al., 2013). Varieties with fast growth, high back yield and good adaptation have recently been obtained though selection from natural resources in China (Du et al., 2013, 2014). However, the effect of selective breeding is restricted by the scarce wild population of $E$. ulmoides (YAO et al., 2012). Moreover, gains in organism growth and the yield of economic secondary metabolites due to heterosis derived from intraspecific hybridisation of E. ulmoides is probably limited, because it is the only extant species of Eucommiaceae (ZHOU, 1993).

An increase in the concentration of secondary metabolites is one of the most valuable effects of polyploidisation (DHAWAN and LAVANIA, 1996). NAKADOZONO et al. (2007) induced 15 tetraploids through seed submerging in colchicine solution. Although some metabolites changed due to chromosome doubling, no significant changes were found in association with the increase of ploidy level in terms of the content and molecular weight distribution of the rubber. To produce triploids of $E$. ulmoides through unilateral sexual polyploidization, GAO et al. $(2004,2009)$ treated the male flowers using both colchicine and high temperatures, and obtained $49.5 \%$ and $70.2 \% 2 \mathrm{n}$ pollen respectively. However, pollination with induced mixed pollen containing a high percentage $2 \mathrm{n}$ grains failed to produce polyploidy progeny (GAO, 2006).

The mode of hybridisation between $n$ eggs and $2 \mathrm{n}$ pollen is considered to be uncommon in origin of polyploids, because $2 \mathrm{n}$ pollen does not compete well with $\mathrm{n}$ pollen (HARLAN and DE WET, 1975). In white poplar, KANG and ZHU (1997) found that $2 \mathrm{n}$ pollen grains germinated tardily and abnormally compared to normal $\mathrm{n}$ pollen, which resulted in poor competition in fertilization of $2 \mathrm{n}$ pollen. A similar tardy germination and low germination rate of high ploidy pollen were reported in blueberry and citrus (VoRsA and ORTIZ, 1992; AlEZA et al., 2012). However, VAN BREUKELEN (1982) reported that $2 \mathrm{x}$ pollen of Solanum tuberosum grew faster that $\mathrm{x}$ pollen in styles, leading to a larger number of ovules fertilised by $2 \mathrm{x}$ pollen. In Lotus tenuis, $2 \mathrm{n}$ pollen also germinated well, although branched pollen tubes were observed (RIM and BeuselincK, 1996). For E. ulmoides, the germination characteristics of $2 \mathrm{n}$ pollen are still unclear, limiting our understanding of the effects of certation.

In the present study, we investigated the reason for the lack of polyploid production after pollination with ploidy-mixed pollen. The morphological variation of heat-treated pollen grains $E$. ulmoides was analysed by light and scanning electron microscopes (SEM) and the germination characteristics of different pollen, including germination rate, tube growth and nucleus development, were compared by in vitro tests.

\section{Materials and Methods}

\section{Plant materials}

Normal untreated pollen was collected from a male plant of $E$. ulmoides growing at the campus of Beijing Forestry University. Ploidy-mixed pollen, with approximately $45 \% 2 \mathrm{n}$ pollen, was obtained by heat shock treatment in the same plant according to GAO et al. (2009), who found that the $45-47^{\circ} \mathrm{C}$ for $3-4 \mathrm{~h}$ is suitable for $2 \mathrm{n}$ pollen induction of $E$. ulmoides. Briefly, the male flower buds were collected from the plant for meiosis observation every 3 hours. When pollen mother cells developed into diakinesis, flower branches were exposed to a temperature of $46^{\circ} \mathrm{C}$ for $4 \mathrm{~h}$ using a patent device (KANG et al., 2007). The pollen samples were collected when maturity and used for morphological observation and were germinated immediately.

\section{Morphological observation of pollen grains}

The morphology of pollen was examined using both light and SEM. For light microscopic observation, pollen samples were stained with $2 \%$ aceto-carmine on a slide to indicate the difference in pollen size. Because it is difficult to ensure the orientation of pollen axis on the aceto-carmine stained slides, the measurements of pollen length and width were conducted based on SEM photographs. For SEM examination, air-dried pollen was mounted directly on aluminum holders using one-sided sticky tape, and sputter-coated with $\mathrm{Au} / \mathrm{Pd}$. The photomicrographs were captured using a Hitachi S-3400N II SEM. The length and width of 100 untreated grains and 184 heat-treated grains were measured randomly by reference to scales. 


\section{In vitro germination and analysis of pollen}

Following You et al. (2014), freshly collected pollen samples were cultured at a concentration of $0.25 \mathrm{mg} \cdot \mathrm{mL}^{-1}$ in a liquid medium containing $200 \mathrm{~g} \cdot \mathrm{L}^{-1}$ sucrose, $30 \mathrm{mg} \cdot \mathrm{L}^{-1}$ boron acid and $10 \mathrm{mg} \cdot \mathrm{L}^{-1}$ calcium nitrate $(\mathrm{pH}$ 6.8) with 100 rpm rotation at $26^{\circ} \mathrm{C}$ to examine the germination characteristics.

After fixation in $4 \%$ paraformaldehyde, the samples were observed at $2,4,6,8,12,18,24$, 32,40 and $48 \mathrm{~h}$ after culturing (HAC) to determine any changes in germination rate and tube length. Pollen grains with tubes longer than their diameters were considered to have germinated (ABDELGADIR et al., 2012). At least 300 pollen grains were observed in each observation to analyze the germination rate. The length of the tube was measured from the germinal pore to the top of the tube using an ocular micrometer. Fixed pollen tubes were stained with 4',6-diamidino-2-phenylindole (DAPI) to determine the position and development of pollen nuclei. More than 50 tubes were randomly selected to measure the tube length and determine the nucleus location in each observation.

\section{Statistical analysis}

Analyses of variance (ANOVA) among untreated pollen, induced small pollen and induced large pollen were performed on pollen length, germination rate and tube length, and the means were compared using a protected least significant difference (LSD, $P<0.05$ ). Prior to analysis, the germination rate data were transformed by the arcsine of the square root of $\mathrm{p} / 100$. The mean widths of untreated and induced pollen were compared using an unpaired $t$-test. Pearson's correlation coefficient was calculated for the relationship between pollen length and width. All statistical analyses were performed using SPSS software (version 18.0).

\section{Results}

\section{Morphological variation of between untreated and heat-treated pollen}

The $2 \mathrm{n}$ pollen grains were larger than normal haploid pollen grains (Fig. 1a). The SEM analysis showed that both untreated pollen and the small pollen grains in heat-treated pollen had three germinal pores (Fig. 1, panels b and c, respectively), but the $2 \mathrm{n}$ pollen had four pores (Fig. 1d). In addition, the germinal furrows became shallow in some large pollen grains (Fig. 1e).

The length of heat-treated pollen grains varied from 24.97 to $39.25 \mu \mathrm{m}$, with an average of $31.89 \mu \mathrm{m}( \pm 3.76)$, while the length of untreated grains ranged from 26.05 to $35.20 \mu \mathrm{m}$, with a mean of $31.67 \mu \mathrm{m}( \pm 1.53)$. Histograms of the distribution of pollen length showed that the length of untreated pollen followed an approximate Gaussian frequency distribution, but the

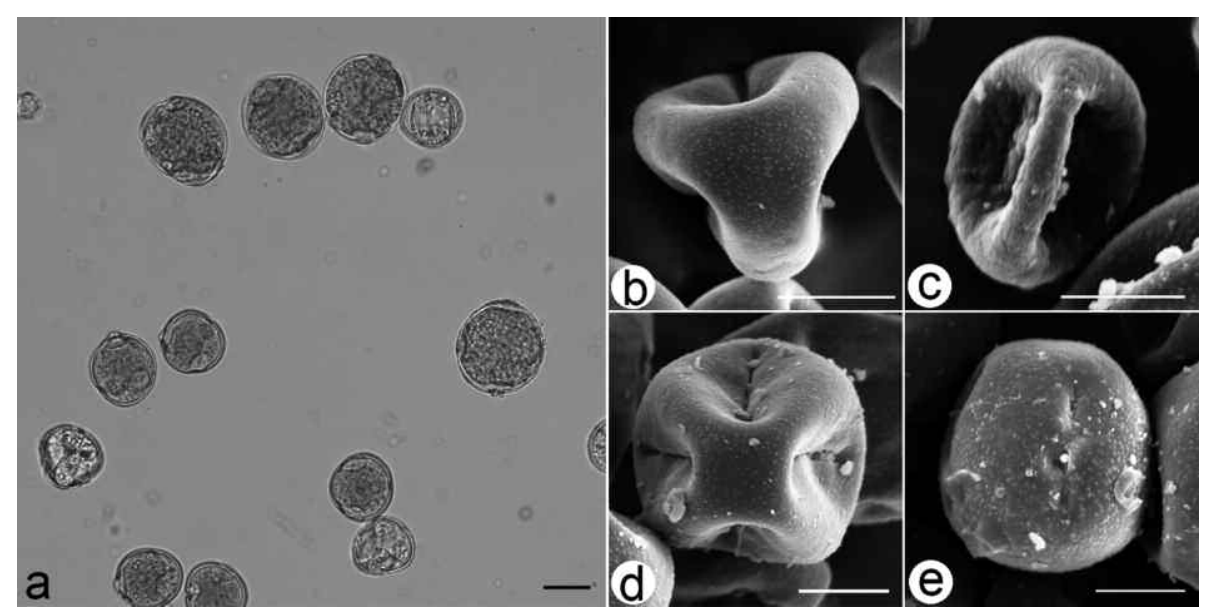

Figure 1. - Morphology of untreated pollen and heat-treated pollen in Eucommia ulmoides.

a. Heat-treated pollen grains under a light microscope showing the difference in size. b. Untreated pollen grain under SEM with three germinal pores. c. Treated small grain with three pores. d. Treated large grain with four pores. e. Treated large grain showing shallow furrows. Bars are equal to 20 $\mu \mathrm{m}$ in (a) and to $10 \mu \mathrm{m}$ in $(\mathbf{b})-(\mathbf{e})$. 

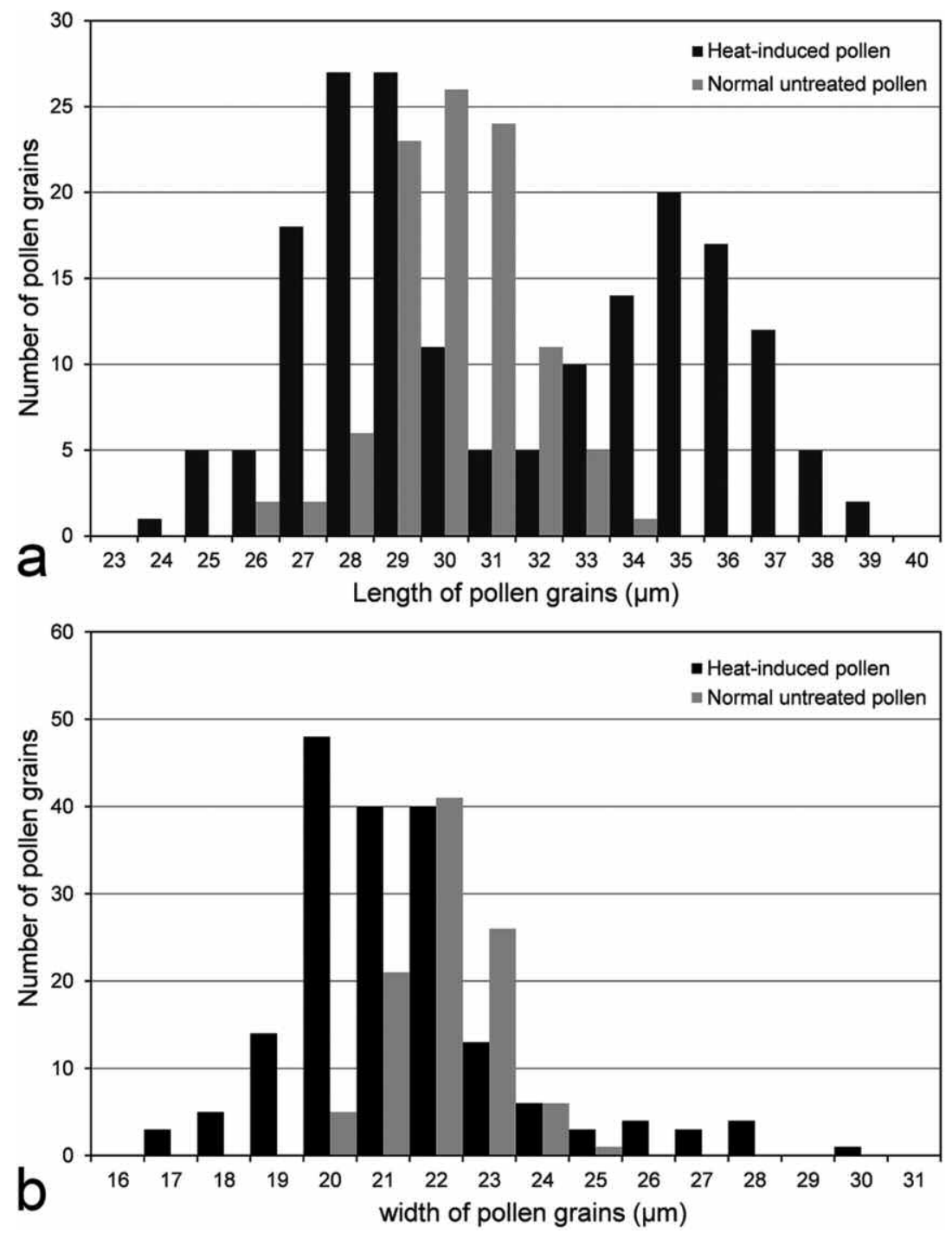

Figure 2. - Frequency distributions of the length and width of untreated and heat-treated pollen grains.

a. Frequency distributions of untreated and heat-treated pollen length. b. Frequency distributions of untreated and heat-treated pollen width.

length of the heat-treated pollen had a bimodal frequency distribution (Fig. 2a), suggesting a divergence of ploidy level. We divided the treated pollen grains into small and large groups, with a threshold of $32 \mu \mathrm{m}$, which was the lowest position between the two peaks. The mean pollen length for the treated small pollen grains and large grains was $28.68 \mu \mathrm{m}( \pm 1.44)$ and $35.63 \mu \mathrm{m}( \pm 1.62)$, respectively. The ANOVA revealed a significant difference in length between the untreated pollen, treated small pollen and treated large pollen $(P<0.0001)$. The length of the treated large pollen was significantly larger than that of the untreated pollen $(P<0.0001)$ and the length of treated small pollen was significantly smaller than that of the untreated pollen $(P<0.0001)$.
The width of the untreated pollen and heattreated pollen arranged from 20.17 to $25.29 \mu \mathrm{m}$ $($ mean $=22.63 \pm 1.00 \mu \mathrm{m})$ and from 17.48 to 30.52 $\mu \mathrm{m}($ mean $=21.85 \pm 2.15 \mu \mathrm{m})$, respectively, which suggested that the high-temperature treatment increased the variation in pollen width. The unpaired $t$-test indicated a significant difference between the mean widths of untreated and heat-treated pollen $(t=4.1870, P<0.0001)$. The width of both the untreated and treated pollen followed approximate Gaussian frequency distributions (Fig. 2b), suggesting that exposure to high temperature did not diverge the width of pollen grains. The width of treated pollen grains was strongly correlated with the length ( $r=0.5396, P<0.0001)$, indicating that the large pollen grain probably also had a large width. 


\section{Germination characteristics of different sized pollen}

Untreated pollen, and heat-treated small and large pollen were all able to germinate in vitro (Figs. $3 a$ and $b$ ), but their germination rates were different (Fig. 3c). The germination rate of the untreated pollen reached $17.50 \pm 0.82 \%$ within the first $2 \mathrm{~h}$ of culturing and increased sharply before 6 HAC. Nearly $38 \%$ of the untreated pollen grains germinated after incubation for $6 \mathrm{~h}$. The percentage germinating continued to gradually increase and reached a maximum of $48.59 \pm 2.18 \%$ at $48 \mathrm{HAC}$. In contrast, although the heat-treated small and large pollen had similar germination rates (Fig. 3a), both were significantly lower than the germination rate of the untreated pollen, suggesting the low germination potential for heat-treated pollen. Just a few treated small pollen grains $(0.70 \pm 0.09 \%)$ and no large pollen were germinated at $2 \mathrm{HAC}$. Before $18 \mathrm{HAC}$, the germina- tion rate of treated small pollen was significantly higher than that of the large pollen, indicating that the large pollen germinated tardily during the early stages of incubation. The maximal germination percentage was $20.01 \pm 0.80 \%$ for the treated small pollen and $20.00 \pm 1.92 \%$ for the large pollen, and this difference was no significant. In addition, the germination rates of both the treated small and large pollen increased sharply within the first $8 \mathrm{~h}$ incubation, which was later than for the untreated pollen, suggesting that the heat-treated pollen germinated more slowly than the untreated pollen.

The tubes of the untreated pollen were, on average, longer than those of the heat-treated pollen (Fig. 3d). Although the tube lengths of the treated small pollen were shorter than those of the untreated pollen, their development was similar (Fig. 3d) with rapid growth after 24 $\mathrm{h}$ incubation. The tube length of the untreated

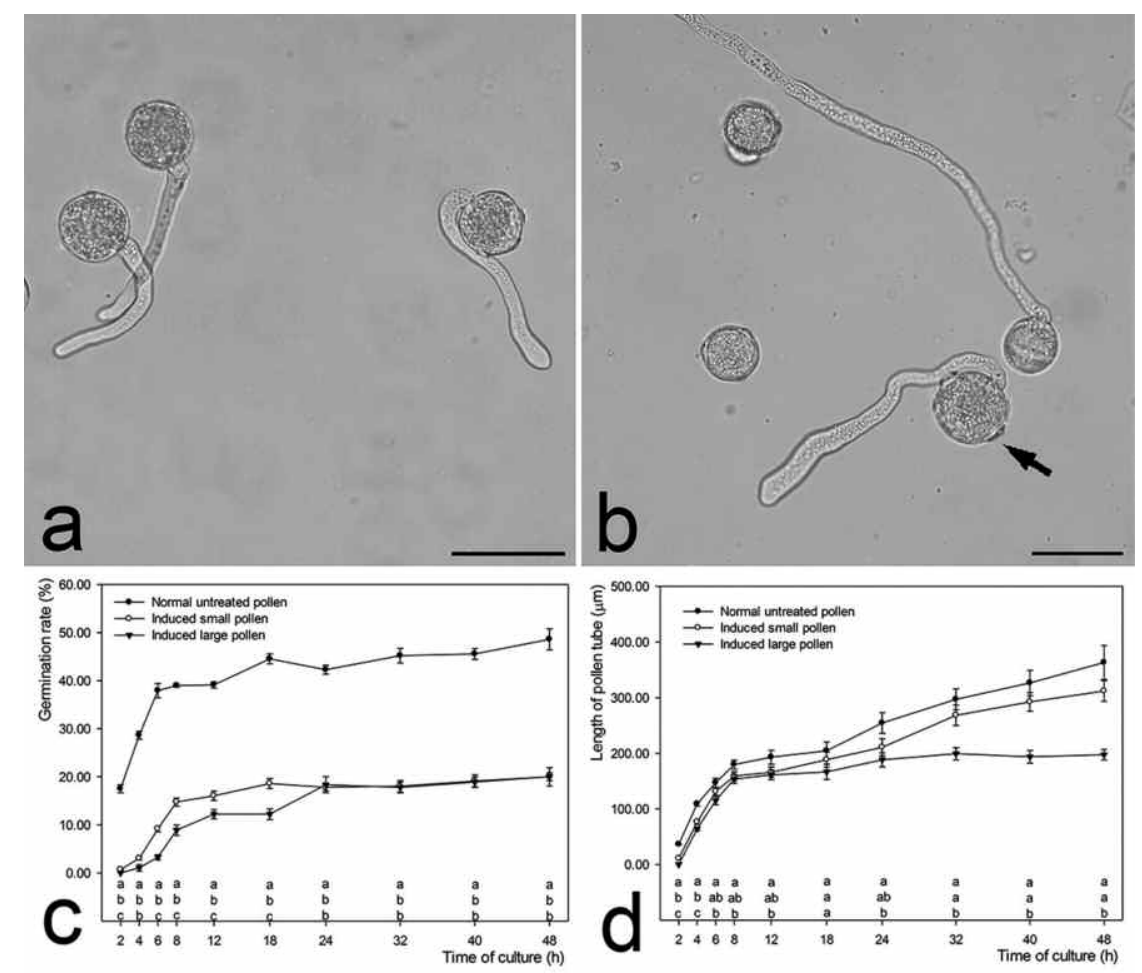

Figure 3. - Germination characteristics of untreated, and heat-treated small and large pollen.

a. Germinating untreated pollen grains. b. Germinating treated small and large (arrow) pollen grains. c. The change in germination rate of pollen with incubation time. d. The change of pollen tube length with incubation time. Bars in (a) and (b) are equal to $50 \mu \mathrm{m}$. The lower cases in (c) and (d) represent significant differences among untreated pollen, treated small pollen and large pollen for the same incubation time according to a Least Significant Difference (LSD) test $(P<0.01)$. The first, second and third lines of lower cases in (c) and (d) are corresponding to untreated pollen, treated small pollen and large pollen, respectively. Error bars indicate standard error. 

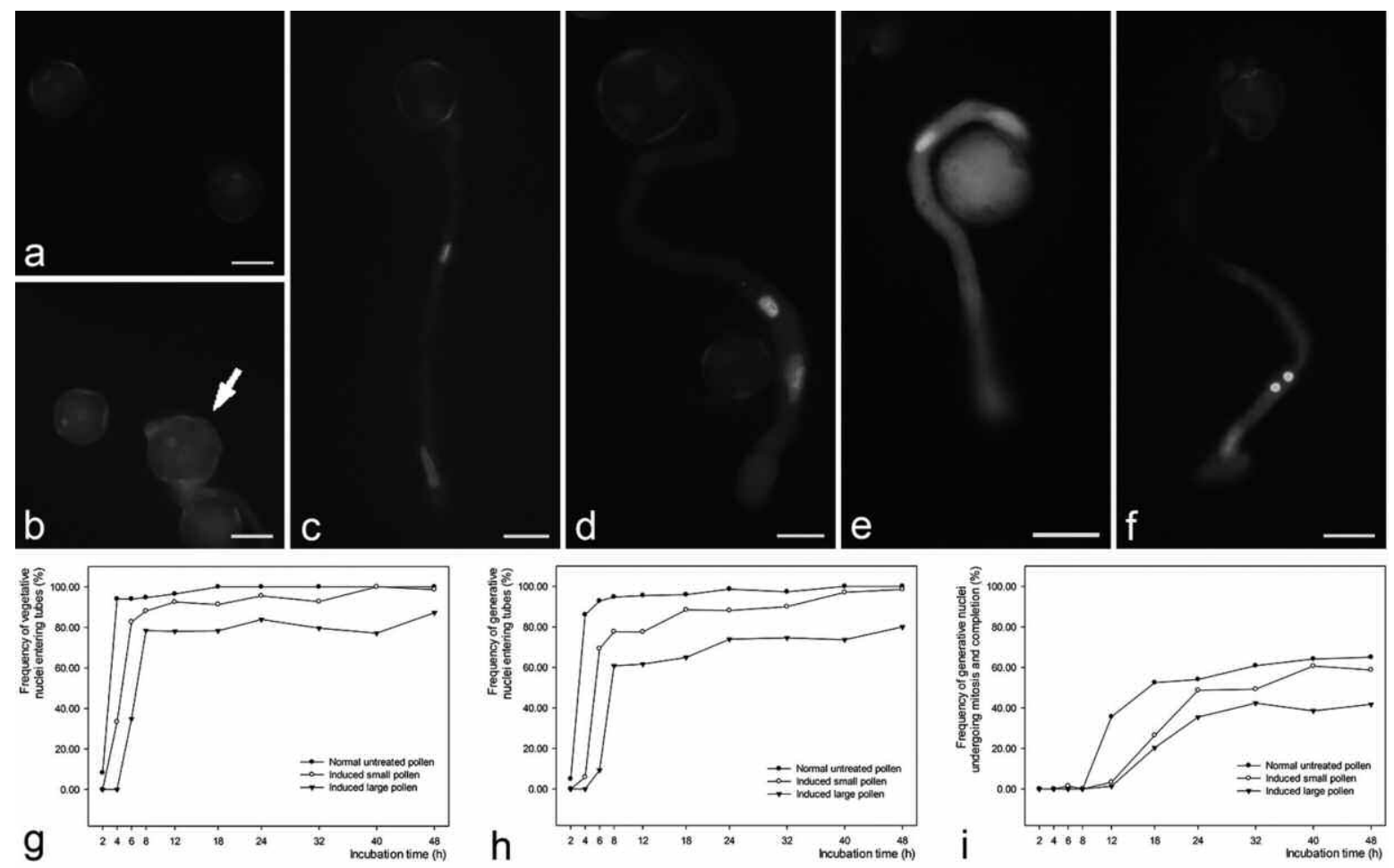

Figure 4. - Movement and development of nuclei of untreated pollen, heat-treated small pollen and large pollen in different incubation time.

a. Vegetative and generative nuclei in untreated pollen grains. b. Nuclei in treated small and large (arrow) pollen grains. c. Vegetative nucleus ahead of generative nucleus in a pollen tube. d. The nuclei in the tube of large pollen. e. Generative nucleus ahead of vegetative nucleus in a pollen tube. f. Sperms developed from a generative nucleus after mitosis in a tube. $\mathbf{g}$. The changing frequency of vegetative nuclei in tubes with incubation time. $\mathbf{h}$. The changing frequency of generative nuclei in tubes with incubation time. i. The changing frequency of generative nuclei carried out mitosis with incubation time. Bars in (a)-(f) are equal to $20 \mu \mathrm{m}$.

pollen and treated small pollen reached $363.14 \pm 30.51 \mu \mathrm{m}$ and $311.84 \pm 18.51 \mu \mathrm{m}$ after $48 \mathrm{~h}$ incubation. In contrast, the tube length of the large pollen remained constant at nearly $200 \mu \mathrm{m}$, which was significantly lower than that of both untreated pollen and treated small pollen, suggesting that the tubes of the large pollen did not grow well in the late period of germination.

\section{Development and movement of pollen nuclei}

Both small and large pollen of Eucommia ulmoides are two-celled, with no mitosis occurring in the generative nucleus (Figs. $4 a$ and $b$ ). Generally, the vegetative nucleus entered into the pollen tube ahead of the generative nucleus (Figs. $4 c$ and $d$ ), but tubes where the generative nucleus entered first were also observed (Fig. 4e). For untreated pollen, both vegetative and generative nuclei entered into the tube rapidly within the first $4 \mathrm{~h}$ incubation (Figs. $4 g$ and $h$ ). When the untreated pollen germinated after $18 \mathrm{~h}$, all of the vegetative nuclei were in the tubes of germinated grains. All generative nuclei entered the tubes of germinated pollen grains at $40 \mathrm{HAC}$. Compared to the untreated pollen, the vegetative and generative nuclei of both heat-treated small and large pollen grains always moved more slowly (Figs. $4 g$ and $h$ ). The treated small pollen grains moved their nuclei into the tubes after $2 \mathrm{~h}$ incubation. Although the vegetative nuclei of the treated small pollen could completely enter into the tube, the frequency of tubes with generative nuclei did not reach $100 \%$ until 48 HAC. The treated large pollen began to move their nuclei into tubes later (after $4 \mathrm{~h}$ incubation). Within $48 \mathrm{~h}$ incubation, the maximal frequencies of tubes with vegetative and generative nuclei in the large pollen were $87.27 \%$ and $80.00 \%$ respectively, suggesting that not all nuclei of the large pollen were able to move into the tubes. 
Mitosis of the generative nucleus followed, forming sperms in the tube (Fig. 4f). Almost all pollen samples began the mitosis of generative nuclei after $8 \mathrm{~h}$ incubation (Fig. $4 i$ ). However, not all germinated grains completed the mitosis. The maximal frequency of tubes completing mitosis in untreated pollen samples was $65.04 \%$, which was higher than in both heattreated small and large pollen $(60.71 \%$ and $42.37 \%$ respectively), suggesting that the generative nuclei of the heat-treated pollen did not divide well.

\section{Discussion}

Unreduced pollen production has received substantial attention with regard to sexual polyploidisation because of its easy detection by size. Cell size increases with increasing DNA content (BRETAGNOLLE and THOMPSON, 1995). For species with spherical pollen grains, the pollen diameter can be used directly to estimate the production of $2 \mathrm{n}$ pollen (ORTIZ, 1997; FALISTOCCO et al., 1995; MASHKINA et al., 1989). However, E. ulmoides have olivary pollen grains with a polar and equatorial axis. In our study, although the width (equatorial diameter) of the heat-treated pollen approximately followed a Gaussian frequency distribution, the pollen length (polar axis) conformed to a bimodal frequency distribution. This is consistent with the frequency distribution of the pollen diameter in unreduced pollen producers (TONDINI et al., 1993; WANG et al., 2010a), suggesting that the high-temperature treatment resulted in the divergence of pollen size and production of $2 \mathrm{n}$ pollen grains. In $E$. ulmoides, the length of pollen grains could be considered to be a criterion for distinguishing pollen with a high ploidy level, which is also possible in oat (KATSIOTIS and ForsBerg, 1995). The range of both lengths and widths of the treated pollen was wider than for the untreated pollen, suggesting that the heat stress might lead to meiotic cytokinesis defects (OKAZAKI et al., 2005; PÉCRIX et al., 2011).

The number of germinal pores in pollen grains usually increases with changes in the ploidy level (CRAMER, 1999). In Trifolium, diploid plants produce almost exclusively pollen grains with three pores, but the pollen grains of chromosome-doubled plants predominantly have more than three germinal pores (NAJČEVSKA and Speckmann, 1968). Cramer (1999) reported that diploid plants of Geranium have 1 to 3 pollen germinal pores $($ mean $=2.1)$, while tetraploid plants have 3 to 5 (mean $=3.8)$. In this study, all of the small pollen grains of E. ulmoides had three germinal pores. However, the $2 \mathrm{n}$ pollen grains typically possessed four pores. Shallow germinal furrows were observed in some large pollen grains. Therefore, the variation in the number of germinal pores could also be used as an indicator to distinguish the production of $2 \mathrm{n}$ pollen (CRAMER, 1999). The variation in germinal pores might affect the germination of pollen grains.

In Populus, 2n pollen germinated tardily and abnormally, resulting in the rare production of triploids after pollination using pollen with a high frequency of $2 \mathrm{n}$ pollen (KANG and ZHU, 1997). In our investigation, the germination rates of both heat-treated small and large pollen of E. ulmoides were lower than the normal untreated pollen, suggesting that high-temperature treatment during meiosis could decrease the viability of pollen (PÉCRIX et al., 2011). Although the maximal germination rates of the treated small and large pollen were not significantly different, the large pollen germinated tardily in early incubation stages, suggesting the tardy germination of $2 \mathrm{n}$ pollen (KANG and ZHU, 1997). The small pollen maintained its growth during incubation, but the growth of the pollen tubes of $2 \mathrm{n}$ pollen almost stopped after $24 \mathrm{~h}$ incubation, indicating that the tubes of $2 \mathrm{n}$ pollen grains did not grow as well as those of $n$ pollen. Both vegetative and generative nuclei in the large pollen moved into tubes later than in the small pollen, and not all of the nuclei in large pollen could enter the tubes. The frequency of generative nuclei conducting mitosis in large pollen was also lower than in the small pollen. This implies that the activities of vegetative and generative nuclei in $2 \mathrm{n}$ pollen might be weaker than in $\mathrm{n}$ pollen. Therefore, the tardy germination, poor tube growth, and weak activity of the vegetative and generative nuclei caused the poor competition of $2 \mathrm{n}$ pollen in certation, resulting in the lack of polyploid production after pollination with induced ploidy-mixed pollen in E. ulmoides (GAO, 2006).

Although competition in the fertilisation of unreduced pollen is low in many plants (HARLAN and DE Wet, 1975; KANG and ZHU, 1997; Vorsa and ORTiZ, 1992; AlezA et al., 2012), some methods have been developed to enhance 
the efficiency of sexual polyploidisation in unreduced pollen. Unreduced pollen grains could be mechanically sieved through a nylon mesh to achieve an enrichment based on the difference in the size between normal and unreduced pollen (EIJLANDER, 1988; TAKAMURA and MiYAJIMA, 2002; OKAZAKI et al., 2005; SUGIURA et al., 2000; ZHANG et al., 1997). Velocity sedimentation has been also used to separate large and small pollen effectively from a heterogeneous mixture of potato (SIMON and SANFORD, 1990). KANG et al. (2000) found a difference in the radio-sensitivity of pollen with different ploidy levels in white poplar, and confirmed that treatment with the correct dosage of ${ }^{60} \mathrm{Co} \gamma$-ray radiation could either kill small pollen or reduce their activity, but large pollen remained active. The frequency of triploid production increased to $12.9 \%$ though pollination with the radiated ploidy-mixed pollen (KANG et al., 2000). In addition, in vitro pollination has been performed with selected unreduced pollen grains in poplar of section Populus to successfully produce triploids (EwALD and Ulrich, 2012). These methods should be used in further studies of sexual polyploidization in $E$. ulmoides, to overcome the poor competition of induced $2 \mathrm{n}$ pollen. However, in vitro pollination might be unfeasible because of the long time for seed maturity (approximately 6 months) in $E$. ulmoides.

Recently, hybridisation with induced $2 \mathrm{n}$ female gametes was confirmed to be an efficient approach for polyploid production (LAI et al., 2015; Li et al., 2008; WANG et al., 2010b, 2012a, b; WU et al., 2007; XI et al., 2014), because competition from normal female gametes could be avoided. It should be noted that WANG et al. (2012b) obtained 146 triploids with high triploid production rate $(60 \%)$, through high-temperature treatments during megasporogenesis in Populus, which exhibited a high efficiency of polyploid production. Both colchicine and high temperature were successfully used in the induction of $2 \mathrm{n}$ female gametes, but the hightemperature treatment had more potential, due to its atoxic, economic and procedural advantages (WANG et al., 2012a, b). The colchicine or high-temperature treatment could be conducted during megasporogenesis and embryo sac development (Li et al., 2008; WANG et al., 2010b, $2012 \mathrm{a}, \mathrm{b})$. The $2 \mathrm{n}$ female gametes characterised by first meiotic division restitution (FDR), second meiotic division restitution (SDR) and post meiotic restitution (PMR) could be induced, depending on the stages of cell development in the enforced treatment (WANG et al., 2010b, 2012a). Different types of $2 n$ gametes can transmit different levels of parental heterozygosity to the progeny (Mendiburu and Peloquin, 1977; BASTIAANSSEN et al., 1998), and have important roles in the improvement of economic traits and genetic studies in crops and trees. Therefore, induction of $2 \mathrm{n}$ female gametes should be included in the polyploid breeding program of $E$. ulmoides, and different methods should be used to produce polyploids.

\section{Acknowledgements}

This work was supported by the Beijing Higher Education Young Elite Teacher Project (Grant No. YETP0758), the National Natural Science Foundation of China (Grant Nos. J1103516 and 31000306), the 111 Project (Grant No. B13007) and the Beijing Nova program (Grant No. Z141105001814007).

\section{References}

Abdelgadir, H. A., S. D. Johnson and J. VAn Staden (2012): Pollen viability, pollen germination and pollen tube growth in the biofuel seed crop Jatropha curcas (Euphorbiaceae). S Afr J Bot 79: 132139.

Aleza, P., J. Juarez, J. Cuenca, P. Ollitrault and L. NAVARRo (2012): Extensive citrus triploid hybrid production by $2 \mathrm{x} \times 4 \mathrm{x}$ sexual hybridizations and parent-effect on the length of the juvenile phase. Plant Cell Rep 31(9): 1723-1735.

Bastiaanssen, H. J. M., P. M. M. M. van Den Berg, P. Lindhout, E. Jacobsen and M. S. Ramanna (1998): Postmeiotic restitution in 2n-egg formation of diploid potato. Heredity 81: 20-27.

Bretagnolle, F. and J. D. Thompson (1995): Gametes with the somatic chromosome number: mechanisms of their formation and role in the evolution of autopolyploid plants. New Phytol 129: 122.

Cramer, C. S. (1999): Laboratory techniques for determining ploidy in plants. HortTechnology 9(4): 594-596.

Dai, X., Q. Huang, B. Zhou, Z. Gong, Z. Liu and S. SHI (2013): Preparative isolation and purification of seven main antioxidants from Eucommia ulmoides Oliv. (Du-zhong) leaves using HSCCC guided by DPPH-HPLC experiment. Food Chem 139(1): 563-570.

DhaWAN, O. P. and U. C. LAVANIA (1996): Enhancing the productivity of secondary metabolites via induced polyploidy: a review. Euphytica 87(2): 8189.

Du, H. Y., L. Y. DU, Y. T. N. Wu and F. H. Li (2013): An elite variety for medicinal use: Eucommia ulmoides 'Huazhong 1'. Sci Silvae Sin 49(11): 195. 
Du, H. Y., L. Y. DU, Y. T. N. Wu and P. F. LIU (2014): An improved variety for samara and medicinal use: Eucommia ulmoides 'Huazhong 3'. Sci Silvae Sin 50(1): 164.

EIJLANDER, R. (1988): Manipulation of the 2ngametes frequencies in Solanum pollen. Euphytica 39(3): 45-50.

EwALD, D. and K. UlRICH (2012): In vitro pollination in poplar of section Populus. Plant Cell Tiss Org 111(2): 255-258.

Falistocco, E., N. Tosti and M. Falcinelli (1995): Cytomixis in pollen mother cells of diploid Dactylis, one of the origins of $2 \mathrm{n}$ gametes. J Hered 86(6): 448-453.

GAO, P. (2006): Gamete and zygote chromosome doubling of Eucommia ulmoides Oliver. Dissertation, Beijing Forestry University.

GAO, P., W. LiN and X. Y. Kang (2004): Pollen chromosome doubling of Eucommia ulmoides induced by colchicine. J Beijing For Univ 26(4): 39-42.

GAO, P., X. Y. KANG, H. G. Yin and S. D. WANG (2009): Induction of $2 \mathrm{n}$ pollen with high temperature in Eucommia ulmoides. Conference Proceeding of Forest Tree Genetics and Improvement at Era of Functional genomics. The Second Forestry Science Conference of China, Nanning, pp 599-604.

HARLAN, J. R. and J. M. J. DE WeT (1975): On “O Winge and a prayer: the origins of polyploidy. Bot Rev 41: 361-390.

KANG, X. Y. and Z. T. ZHU (1997): A study on the 2n pollen vitality and germinant characteristics of white poplars. Acta Bot Yun 19(4): 402-406.

KANG, X. Y., Z. T. ZHU and H. B. LIN (2000): Radiosensitivity of different ploidy pollen in poplar and its application. Acta Genet Sin 27(1): 78-82.

Kang, X. Y., C. Sa, W. W. Zhang, P. GaO, P. D. Zhang and S. D. WANG (2007): A device for in vivo chromosome doubling with high temperature for trees. Chinese Patent, ZL200510011598.5.

Katsiotis, A. and R. A. Forsberg (1995): Pollen grain size in four ploidy levels of genus Avena. Euphytica 83(2): 103-108.

Lai, H. G., X. Chen, Z. Chen, J. Q. Ye, K. M. Li and J. P. LIU (2015): Induction of female $2 \mathrm{n}$ gametes and creation of tetraploids through sexual hybridization in cassava (Manihot esculenta). Euphytica 201(2): 265-273.

LI, Y. H., X. Y. Kang, S. D. Wang, Z. H. Zhang and H. W. CHEN (2008): Triploid induction in Populus alba $\times P$. glandulosa by chromosome doubling of female gametes. Silvae Genet 57: 37-40.

Mashkina, O. S., L. M. Burdaeva, M. M. Belozerova and L. N. Vyunova (1989): Method of obtaining diploid pollen of woody species. Lesovedenie 1: 19-25.

Mendiburu, A. O. and S. J. Peloquin (1977): The significance of $2 \mathrm{n}$ gametes in potato breeding. Theor Appl Genet 49: 53-61.

NAJČEVsKa, C. M. and G. J. SpeCKMANN (1968): Numbers of chloroplasts and pollen grain pores in diploid and tetraploid varieties of some Trifolium species. Euphytica 17(3): 357-362.
Nakadozono, Y., T. Bamba, R. Chen, S. NAmimatsu, Y. NAKAZAWA and K. GYOKUSEN (2007): Induction and analysis of polyploid in Eucommia ulmoides Oliver. In International Symposium on Eucommia ulmoides 1: 112-115.

NakazaWA, Y., T. Takeda, N. Suzuki, T. HaYashi, Y. HARADA, T. BAMBA and A. KoBAyASHI (2013): Histochemical study of trans-polyisoprene accumulation by spectral confocal laser scanning microscopy and a specific dye showing fluorescence solvatochromism in the rubber-producing plant, Eucommia ulmoides Oliver. Planta 238(3): 549-560.

Okazaki, K., K. Kurimoto, I. MiYajima, A. Enami, H. Mizuochi, Y. Matsumoto and H. OHYA (2005): Induction of $2 \mathrm{n}$ pollen in tulips by arresting the meiotic process with nitrous oxide gas. Euphytica 143(1-2): 101-114.

Ortiz, R. (1997): Occurrence and inheritance of $2 \mathrm{n}$ pollen in Musa. Ann Bot-London 79(4): 449-453.

PÉcrix, Y., G. Rallo, H. Folzer, M. Cigna, S. Gudin and M. LE BRIS (2011): Polyploidization mechanisms: temperature environment can induce diploid gamete formation in Rosa sp. J Exp Bot 62(10): 3587-3597.

RIM, Y. W. and P. R. BEuselinck (1996): Cytology of $2 \mathrm{n}$ pollen formation and pollen morphology in diploid Lotus tenuis (Fabaceae). Amer J Bot 83(8): 1057-1062.

Simon, C. J. and J. C. SANForD (1990): Separation of $2 \mathrm{n}$ potato pollen from a heterogeneous pollen mixture by velocity sedimentation. Hortscience 25(3): 342-344.

Sugiura, A., T. Ohkuma, Y. A. Choi, R. TAo and M. TAMURA (2000): Production of nonaploid $(2 \mathrm{n}=9 \mathrm{x})$ Japanese persimmons (Diospyros kaki) by pollination with unreduced $(2 \mathrm{n}=6 \mathrm{x})$ pollen and embryo rescue culture. J Am Soc Hortic Sci 125(5): 609-614.

TAKAmuRA, T. and I. MiYAJIMA (2002): Origin of tetraploid progenies in $4 \mathrm{x} \times 2 \mathrm{x}$ crosses of Cyclamen (Cyclamen persicum Mill.). J Jap Soc Hortic Sci 71(5): 632-637.

Tondini, F., S. TAWoletti, A. Mariani and F. VERONESI (1993): A statistical approach to estimate the frequency of n, $2 \mathrm{n}$ and $4 \mathrm{n}$ pollen grains in diploid alfalfa. Euphytica 69: 109-114.

VAN Breukelen, E. W. M. (1982): Competition between $2 \mathrm{x}$ and $\mathrm{x}$ pollen in styles of Solanum tuberosum determined by a quick in vivo method. Euphytica 31(3): 585-590.

Vorsa, N. and R. Ortiz (1992): Cytology of 2n pollen formation in a blueberry aneuploid $(2 \mathrm{n}=4 \mathrm{x}+9=57)$. J Hered 83(5): 346-349.

WANG, J., X. KANG and Q. ZHU (2010a): Variation in pollen formation and its cytological mechanism in an allotriploid white poplar. Tree Genet Genom 6(2): 281-290.

WANG, J., X. Kang, D. Li, H. Chen and P. Zhang (2010b): Induction of diploid eggs with colchicine during embryo sac development in Populus. Silvae Genet 59: 40-48. 
WANG, J., X. Y. KANG and D. L. LI (2012a): High temperature-induced triploid production during embryo sac development in Populus. Silvae Genet 61: 85-93.

WANG, J., D. LI and X. KANG (2012b): Induction of unreduced megaspores with high temperature during megasporogenesis in Populus. Ann Forest Sci 69: 59-67.

Wu, H., S. Zheng, Y. He, G. Yan, Y. Bi and Y. ZHU (2007): Diploid female gametes induced by colchicine in Oriental lilies. Sci Hortic 114(1): 50-53.

XI, X., L. Guo, W. Xu, J. Zhang and B. Li (2014): Megasporogenesis, megagametogenesis, and induction of $2 \mathrm{n}$ eggs with colchicine in poplar section Aigeiros. Scand J Forest Res 29(6): 527-536.

YAo, X., J. Deng and H. HuAng (2012): Genetic diversity in Eucommia ulmoides (Eucommiaceae), an endangered traditional Chinese medicinal plant. Conserv Genet 13(6): 1499-1507.
You, H., T. JIA, J. TIAN, J. WANG and X. KANG (2014): Characteristics of in vitro pollen germination and microfilament distribution of pollen tubes of Eucommia ulmoides Oliv. Acta Bot Boreal-Occident Sin 34(3): 495-501.

Zhang, Z. Y., F. L. Li, Z. T. ZHU and X. Y. KANG (1997): Doubling technology of pollen chromosome of Populus tomentosa and its hybrid. J Beijing For Univ (English Ed.) 6(2): 9-20.

Zноu, Z. X. (1993): Eucommia ulmoides of China. Guizhou Science and Technology Press, Guiyang.

ZHU, Z., X. KANG and Z. ZHANG (1997): Advances in the triploid breeding program of Populus tomentosa in China. J Beijing For Univ (English Ed.) 6(2): $1-8$.

The English in this document has been checked by at least two professional editors, both native speakers of English. For a certificate, please see: http://www.textcheck.com/certificate/QZ2V8L

\title{
Individual, fruit, and annual variation in correlated mating in a Genipa americana population
}

\author{
By R. O. Manoel ${ }^{1)}$, M. L. M. Freitas ${ }^{2)}$, E. Furlani Júniro ${ }^{1)}$, \\ P. F. AlveS ${ }^{1)}$, M. L. T. Moraes ${ }^{1)}$ and A. M. SebBenN ${ }^{2), *}$
}

(Received 16 ${ }^{\text {th }}$ May 2015)

\begin{abstract}
In this paper, we use six microsatellite loci to examine a spatially isolated population of Genipa americana in relation to mating system variation at the level of individual and among and within fruits, over two reproductive events. For our analysis, we sampled hierarchically among and within fruits open-pollinated seeds collected from 13 seed trees during the reproductive event in 2010 and 12 seed trees in 2011. The rate of mating among relatives $\left(1-t_{s}\right)$ was

1) Ilha Solteira School of Engineering/UNESP, CP 31, Ilha Solteira, São Paulo 15385-000, Brazil.

2) Forestry Institute of São Paulo, Rua do Horto 931, CP 1322, São Paulo, São Paulo 01059-970, Brazil.

*) Corresponding author: A. M. SEBbenn. Forestry Institute of São Paulo, Rua do Horto 931, C.P. 1322, 02377-000, São Paulo, SP, Brazil.

Telephone: +55 1934351681 .

E-Mail: alexandresebbenn@yahoo.com.br
\end{abstract}

significantly greater than zero and different between the investigated reproductive events, indicating that some seeds are inbred. The estimate of fixation index $\left(F_{o}\right)$ was significantly higher than zero for seeds from both reproductive events $\left(2010: F_{o}=0.258 ; 2011: F_{o}=0.294\right)$, confirming that seeds present inbreeding, probably originated from mating among full-sibs. The multilocus paternity correlation within fruits $\left(r_{p(w)}\right)$ and among fruits $\left(r_{p(a)}\right)$ varied among seed trees and reproductive events. The $r_{p(w)}$ was significantly higher than $r_{p(a)}$ in both reproductive events, suggesting that it is more likely to find full-sibs within fruits (2010: 36.4\%; 2011: 72.4\%), than among fruits (2010: 18.9\%; 2011: $12.8 \%$ ). Due to the presence of inbreeding, mating among relatives and correlated mating, the within families coancestry coefficient $(\Theta)$ was higher and the variance effective size $\left(N_{e}\right)$ lower than expected in openpollinated families from panmictic populations 